\title{
Analysis of Factors that Influence The Risk of Accidents in Terms of Behavioral Aspects (Study on Aircraft Paint Removal Workers in PT. X)
}

\author{
Hesti Fiskalisa Purbayanti \\ Department of Occupational Safety and Health \\ Universitas Airlangga \\ Surabaya \\ hestifiskalisa@yahoo.com
}

\author{
Tri Martiana \\ Department of Occupational Safety and Health \\ Universitas Airlangga \\ Surabaya \\ Tri.martiana@fkm.unair.ac.id
}

\begin{abstract}
Aircraft Paint Removal is an activity that has a high risk of occupational accident. The human factor is the main determinant of occupational accident with bad knowledge, attitudes and actions all posing a potential risk. The purpose of this study is to determine the factors that affect the risk of occupational accidents among Aircraft Paint Removal workers in PT. $X$. This research is a cross- sectional study with Chi-Square statistical analysis. Data collection is done by distributing questionnaires to workers. The dependent variable in this research is occupational accident risk and independent variables are knowledge, attitude and action of worker. The population in this study is 62 Aircraft Paint Removal workers, and, following simple random sampling 34 subjects were obtained. The result of Chi-Square statistical test shows that there is influence of knowledge, attitude and action on the risk of occupational accident on Aircraft Paint Removal workers in PT. $X$ is significant with $p$ value 0.026 for knowledge variable, $p$ value 0.00 for attitude variable, and $p$ value 0.001 for action variable.
\end{abstract}

Keywords- aircraft paint removal, risk of occupational accident, behavior

\section{I.INTRODUCTION}

Occupational health and safety is something that must be implemented at every workplace. Occupational safety and health is not only carried out by workers, but by all those who are in the workplace. All work performed by humans has potential hazards that could pose a risk for work accidents and health problems. Potential hazards that exist in the workplace can occur due to the process of doing a job, the use of high-tech machines, tools and materials used, poor working environment, unsafe behavior, non-ergonomic body positions and work culture that is not conducive to occupational health and safety (Kurniawidjaja, 2010). ${ }^{[1]}$
Accident is an event that was originally unexpected and unwanted and the event could disrupt the process that has been arranged from an activity and can cause harm to both human victims and financial losses. BPJS Ketenagakerjaan has noted that there have been 105,182 cases of occupational accidents until the end of 2015 and 2,375 cases of such accidents resulting in death. Low public awareness of the importance of the implementation of occupational health and safety is a major cause of accidents. Occupational health and safety implementation is an investment to prevent occupational accidents, but its implementation is often regarded as a waste of time and money. ${ }^{[2]}$

Users of air transportation services in Indonesia, for both domestic and international flights, continue to increase by an average of $12.5 \%$ per year. Aviation safety is a top priority. In the event of an aviation accident, it will not only cause casualties, but the airline will acquire a bad image and may result in less public trust to use its services. Safety guarantees should be initiated while the aircraft is on the ground and receiving maintenance. Aircraft maintenance is one of the aspects of the airline industry is very important in order to maintain the safety of the flight (Sit et al., 2013). ${ }^{[3]}$

The dangerous behavior of workers is a direct variable that causes accidents. In addition, Heinrich (1959) states that $88 \%$ of accidents are due to unsafe action of a person, $10 \%$ by unsafe condition and $2 \%$ by other causes that can not be predicted. ${ }^{[4]}$ The insecure action is related to the human factor. Workers tend to work based on experience only and do not adhere to the Standard Operating Procedure (SOP) which has been determined. In addition, the behavior of workers who tend to ignore safety is in not using the appropriate Personal Protective Equipment (PPE) provided that should be used when the worker performs his work. ${ }^{[5]}$ 
Based on this explanation, the human factor is the main cause of accidents. ${ }^{[6]}$ Dangerous behavior is one of the human factors that can cause occupational accidents. Dangerous behavior is an unsafe act in doing a job and potentially causing an occupational accident. Dangerous behavior in doing the job is related to the knowledge, attitudes and actions of workers while carrying out their work in the context of the dangers that surround it.

PT. $\mathrm{X}$ is an MRO industry (Maintenance, Repair and Overhaul) for aircraft, components, engines and supporting products. In the work process, PT. X uses high-tech equipment and hazardous and toxic materials (B3). Occupational accident data at PT. X shows that there are 62 nonLost Time Injury (non-LTI) occupational accident and two Lost Time Injury (LTI) accidents. Occurrence of most accidents is on aircraft paint removal jobs. In 2015 and 2016, there were eight workplace accidents on aircraft paint removal work as well as many unrecorded but frequent occurrences of occupational accidents. Such accidents include contact of workers' hands with the chemical fluid used for the removal of aircraft paint. Such occupational accidents can occur because workers are less careful while working and there are still workers who do not use Personal Protective Equipment (PPE) because they feel uncomfortable with it.

Based on the background above, there are several work hazard factors that can lead to occupational accidents. Bad knowledge, attitudes and actions can pose a risk of occupational accidents. Therefore, the authors seek to conduct research on the influence of knowledge, attitude and action on the risk of work accident on aircraft paint removal workers in PT. X. The purpose of this study is to determine the factors that affect the risk of work accidents on Aircraft Paint Removal workers in PT. $\mathrm{X}$.

\section{METHODS}

Based on the time of the research, this study included cross-sectional research because the observation of the variables was performed for a certain period only, while the analysis is through is analytical research. This research was conducted on aircraft paint removal work in PT. X located at Soekarno-Hatta International Airport, Cengkareng. The population in this study is 62 aircraft paint removal workers. Sampling method was done by simple random sampling and a sample of 34 people was obtained.

Data collection methods in this study were conducted by distributing questionnaires to aircraft paint removal workers. The questionnaire used is a questionnaire that has been used by researchers in previous research, and was then further developed by the researchers. Independent variables from this research are knowledge, attitude and action of aircraft paint removal workers, while the dependent variable is occupational accident risk. Variables used in this study were measured by way of scoring on each item of question then categorized with ordinal scale measurement.

Gutman scale is the measurement aspect used in this research. The Gutman scale is a scale used for answers that want a firm answer type, such as "correct" or "false" answers to a "yes" or "no" knowledge questionnaire and answers to a risk occupational accident, attitude and action questionnaire.

Determination of score using Gutman scale is done by looking at the highest score difference of each questionnaire and obtaining the interval so that the difference is $50 \%$. Measurements on the dependent variable, which is the risk of occupational accident, is given based on six questions with the alternative answer "yes" given score 1 and "no" given score 0 ; thus, the overall total score is 6 . Once the total score is known, the risk of occupational accident is categorized into low if the final assessment result scores $\geq 50 \%$ (score $3-6$ ). Risks include high categories if the respondent scores $<50 \%$ (score $0-2$ ).

Measurement of independent variables is given based on the attitude of the eight questions with alternative answers "yes" to the question numbers 1 , 2, 3, 5, 6 and 7 are given a score of 0 and "no" is given a score of 1 , while for the numbers 4 and 8 , a "yes" answer is given a score of 1 and " no" is given a score of 0 . The total score is 8 . After obtaining the total score, the attitude variable is categorized into good if the respondent scored $\geq 50 \%$ (number of score 4-8) and not good if respondent scored $<50 \%$ (total score 0-3).

Measurement of independent variable action is based on the eight questions with alternative answers "yes" in numbers 1, 2, 4, 6, 7 and 8 given a score of 1 and "no" is given a score of 0 , whereas in question 3 and 5 answer "yes" is given a score of 0 and the answer "no" given a score of 1 . The total score is 8 . The action variable is categorized to be good if respondents score $\geq 50 \%$ (number of score $4-8$ ) and not good if respondents score $<50 \%$ (total score $0-3$ ).

Data analysis conducted in this research includes univariate analysis and bivariat analysis. Univariate analysis is an analysis that describes independent variables singly. Independent variables in this study include knowledge, attitude and action and also the dependent variable is the risk of occupational accident in the form of frequency distribution. Bivariate analysis is used to explain the relationship between independent variables (knowledge, attitude and action) with the dependent variable (the risk of accident). 


\section{RESULT}

Below is the working process of aircraft paint removal:

\section{Masking}

Masking is a process of closing areas that will not be repainted. These areas are glass windows, cockpit glass and parts of aircraft made of composite materials. The areas are covered using a plastic that is glued together with an adhesive made of aluminum

\section{Apply Stripping}

Stripping is the process of exfoliating aircraft paint by using a chemical called a paint stripper containing hydrogen peroxide. Paint stripper is applied by spraying using a spray gun. When finishing being applied to areas that are not in masking, the paint stripper (Turco 6930) is left for three hours. The residual of the old paint is then cleaned using a wiper and hot water by spraying using a water spray gun pump. The next step is to apply a stripper (Turco 5351) using a brush on an area that still has residual of old paint.

\section{Sanding}

The sanding process is to apply a sander to areas made of composite material. The purpose of the sanding process is to remove the sparkling effect of the old paint in order for the new paint to adhere perfectly.

\section{Apply Protective Treatment}

This process is done by smearing the chemical fluid (Allodine 1200) on the plane exterior made of metal only. The chemical fluid serves to protect the exterior of the aircraft to avoid corrosion.

Based on the work process of aircraft paint removal, accidents that occur are workers falling from a height because workers do not use PPE (safety body harness) and being hit by a sharp part of the aircraft like a galley door and antenna, causing lesions. When masking in the window, the worker's hands can be hit by a cutter knife and cause bleeding. Another accident is hot water from the gun of the hot water pressure cleaner on the skin of workers causing blisters. In addition, there are frequent occupational accidents such as exposed paint stripper on the hands because workers do not use PPE (latex gloves).

Univariate analysis is used to show frequency distribution and percentage of each independent variable, which are knowledge, attitude and action, and dependent variable, which is the risk of occupational accident. Based on Table 1 below, worker knowledge on Occupational Health and Safety in aircraft paint removal workers at PT. X included in the 'good' category is equal to $64.7 \%$. There are 23 workers having good knowledge and $11(35.3 \%)$ having poor knowledge

Table 1. Frequency Distribution of Occupational Health and Safety Knowledge in Aircraft Paint Removal Workers at PT. X.

\begin{tabular}{|l|l|l|l|}
\hline No & Knowledge & Frequency & $\%$ \\
\hline 1. & Good & 23 & 64.7 \\
\hline 2. & Not Good & 11 & 35.3 \\
\hline Total & & 34 & 100 \\
\hline
\end{tabular}

Based on Table 2 below, work attitude on aircraft paint removal workers in PT. X included in the 'not good' category is equal to $52.9 \%$. There are 18 workers with a bad attitude of work, while there are 16 workers with a good working attitude $(47.1 \%)$.

Table 2. Frequency Distribution of Work Attitude In Aircraft Paint Removal Workers at PT. X

\begin{tabular}{|l|l|l|l|}
\hline No. & Attitude & Frequency & $\%$ \\
\hline 1. & Good & 16 & 47.1 \\
\hline 2. & Not Good & 18 & 52.9 \\
\hline Total & & 34 & 100 \\
\hline
\end{tabular}

Based on Table 3 below, it can be seen that the actions of workers while doing aircraft paint removal in PT. X included in the 'not good' category is equal to $52.9 \%$. There are 16 workers in the good action category (47.1) with a smaller percentage of 18 workers with bad actions.

Table 3. Frequency Distribution of Actions on Aircraft Paint Removal Workers at PT. X

\begin{tabular}{|l|l|l|l|}
\hline No & Actions & Frequency & $\%$ \\
\hline 1. & Good & 14 & 41.2 \\
\hline 2. & Not Good & 20 & 58.8 \\
\hline Total & & 34 & 100 \\
\hline
\end{tabular}

Based on Table 4 below, it can be seen that there are 12 workers who are at high risk of having work accidents $(35.3 \%)$ and $22(64.7 \%)$ do not have a high risk for accidents.

Table 4. Frequency Distribution of The Risk of Accidents in Aircraft Paint Removal Workers at PT. X

\begin{tabular}{|l|l|l|l|}
\hline No. & $\begin{array}{l}\text { Risiko } \\
\text { Kecelakaan } \\
\text { Kerja }\end{array}$ & Frekuensi & $\%$ \\
\hline 1. & Low risk & 22 & 64.7 \\
\hline 2. & High risk & 12 & 35.3 \\
\hline Total & & 34 & 100 \\
\hline
\end{tabular}

Bivariate analysis is used to explain the relationship between independent variables, consisting of knowledge, attitude and action, with dependent variable, which is the risk of accidents. 
Based on Table 5, it can be seen that the lack of knowledge of workers about Occupational Health and Safety is also increasingly at risk of accidents. It can be seen that there are 11 workers who have poor knowledge people $(32.4 \%)$ and there are seven $(20.6 \%)$ who are at high risk of occupational accidents. While 23 workers $(67.6 \%)$ have good knowledge there are only five who have a high risk of occupational accidents.

The result of statistical test with Chi-Square shows that $p$ value $<0.05(p=0.026)$. It shows that there is influence of knowledge of work accident risk on aircraft paint removal workers in PT. X

\begin{tabular}{|c|c|c|c|c|c|c|c|c|}
\hline \multirow[b]{3}{*}{ No. } & \multirow[b]{3}{*}{ Knowledge } & \multicolumn{4}{|c|}{ The Risk of Occupational Accidents } & \multirow{2}{*}{\multicolumn{2}{|c|}{ Total }} & \multirow{3}{*}{ p- value } \\
\hline & & \multicolumn{2}{|c|}{ Low } & \multicolumn{2}{|c|}{ High } & & & \\
\hline & & $\mathrm{N}$ & $\%$ & $\mathrm{~N}$ & $\%$ & $\mathrm{~N}$ & $\%$ & \\
\hline 1. & Good & 18 & 52.9 & 5 & 14.7 & 23 & 67.6 & 0.026 \\
\hline 2. & Not Good & 4 & 11.8 & 7 & 20.6 & 11 & 32.4 & \\
\hline \multicolumn{2}{|c|}{ Total } & & & & & 34 & 100 & \\
\hline
\end{tabular}

Based on Table 6, it can be seen that there are 16 workers who have a good working attitude is $(47.1 \%)$ and there are only four having a high risk of occupational accidents. Meanwhile, for workers with poor work attitude, it can be seen that from 18 workers with poor working attitude, all 18 workers are at high risk of occupational accident.
The result of statistical test with Chi-Square shows that $p$ value $<0.05(p=0.000)$. It shows that there is influence of work attitude to the risk of occupational accident on aircraft paint removal workers in PT. X.

Table 6. Effect of Workers' Attitudes on The Risk of Accidents

\begin{tabular}{|c|c|c|c|c|c|c|c|c|}
\hline \multirow[b]{3}{*}{ No. } & \multirow[b]{3}{*}{ Attitude } & \multicolumn{4}{|c|}{ The Risk of Occupational Accidents } & \multirow{2}{*}{\multicolumn{2}{|c|}{ Total }} & \multirow{3}{*}{ p-value } \\
\hline & & \multicolumn{2}{|c|}{ Low } & \multicolumn{2}{|c|}{ High } & & & \\
\hline & & $\mathrm{N}$ & $\%$ & $\mathrm{~N}$ & $\%$ & $\mathrm{~N}$ & $\%$ & \\
\hline 1. & Good & 12 & 35.3 & 4 & 11.8 & 16 & 47.1 & \multirow{3}{*}{0.000} \\
\hline 2. & Not Good & 0 & 0 & 18 & 52.9 & 18 & 52.9 & \\
\hline Tota & & 12 & 35.3 & 22 & 64.7 & 34 & 100 & \\
\hline
\end{tabular}

Based on Table 7 below, it can be seen that there are 14 workers having good actions (41.2\%) and there are only four $(11.8 \%)$ who have a high risk for the occurrence of occupational accidents. Meanwhile, for workers who have bad actions there are as many as 20 people $(58.8 \%)$ and there are 18 $(52.9 \%)$ at high risk for occupational accidents. The result of statistical test with Chi-Square shows that $\mathrm{p}$ value $<0.05(\mathrm{p}=0.001)$. It shows that there is influence of worker action on work accident risk on aircraft paint removal workers in PT. X.

Table 7. Effect of Workers' Action on The Risk of Occupational Accidents

\begin{tabular}{|c|c|c|c|c|c|c|c|c|}
\hline \multirow[b]{3}{*}{ No. } & \multirow[b]{3}{*}{ Action } & \multicolumn{4}{|c|}{ The Risk of Occupational Accidents } & \multirow{2}{*}{\multicolumn{2}{|c|}{ Total }} & \multirow{3}{*}{ p-value } \\
\hline & & \multicolumn{2}{|c|}{ Rendah } & \multicolumn{2}{|c|}{ Tinggi } & & & \\
\hline & & $\mathrm{N}$ & $\%$ & $\mathrm{~N}$ & $\%$ & $\mathrm{~N}$ & $\%$ & \\
\hline 1. & Baik & 10 & 29.4 & 4 & 11.8 & 14 & 41.2 & \multirow{3}{*}{0.001} \\
\hline 2. & $\begin{array}{l}\text { Tidak } \\
\text { baik }\end{array}$ & 2 & 5.9 & 18 & 52.9 & 20 & 58. & \\
\hline Tota & & 12 & 35.3 & 22 & 64.7 & 34 & 100 & \\
\hline
\end{tabular}

\section{DISCUSSION}

Based on the results of univariate analysis of 34 workers, there are 23 workers who have knowledge about Occupational Health and Safety in the 'good' category. On the other hand, 11 workers have knowledge about Occupational Health and Safety in the 'not good' category. Based on this, it can be concluded that worker knowledge about
Occupational Health and Safety is good because most workers already have good knowledge. Based on the results of the workers' answers to the completed questionnaires, most workers do not know how to prevent accidents. Knowledge of Occupational Health and Safety and is essential in understanding safety behavior, since the knowledge gained can be applied when doing the work. ${ }^{[7]}$ If the worker has a sound knowledge of Occupational 
Health and Safety, then the worker can better understand the potential dangers that exist in their work. Workers who know the potential dangers that exist in their work will be more careful in doing it.

Based on univariate analysis on work attitude of 34 workers, there are 16 with good working attitude and 18 with bad work attitude. The number of workers with poor work attitude is more important than workers with a good working attitude. Most workers who have a work attitude of 'not good' do not agree in using complete personal protective equipment when working and workers also do not adopt an ergonomic body position while working. Attitude is more emphasized on individual evaluation of the object of attitude, such as the definition proposed by Eagly and Cahiken that attitude is a psychological tendency shown by the assessment of happy or not pleased with an object. [8] Meanwhile, the knowledge of Occupational Health and Safety is a science and its application is useful to prevent the occurrence of work accidents caused by work. Based on the explanation, the definition of attitudes toward knowledge about Occupational Health and Safety emphasizes the existence of evaluation to agree or disagree with knowledge.

Based on univariate analysis on the actions of 34 workers, there were 14 with good action and 20 with bad actions. Therefore, it can be concluded that, from the majority of workers, most still have a bad work action. Based on observations and interviews using questionnaires, there are still many aircraft paint removal workers in PT. X who have bad habits while working. Bad habits while working are, among others, less focused and less careful and do not use Personal Protective Equipment. Action can be errors or omissions committed by humans. Those mistakes are skill-based errors, errors in compliance with rules and procedures (rule-based error) and mistakes in the decision-making process due to lack of knowledge (knowledge-based error) .

In accordance with the results of bivariate analysis using Chi-Square statistical test for the three independent variables of knowledge, attitude and action, all independent variables have an influence on the dependent variable, which is the risk of occupational injury.

\section{Influence of knowledge on work accident risk}

One of the efforts that can be done to improve individual knowledge is through education and training, both formally and informally, including knowledge about everything that is at risk to the occurrence of work accident and health problems. In addition, accidents can be prevented and such prevention is based on the knowledge of the reasons why the accident could happen. If the workers have good knowledge of Occupational Health and Safety, the worker is able to understand safety well and this is the most important component in maintaining his safety from the risks of the work in hand. The results of this study are in accordance with research conducted by Cheng et al. which says that there is a relationship between workers' knowledge and the occurrence of accidents. ${ }^{[9]}$

\section{Influence of Attitudes on Occupational Risk}

There is influence of work attitude to the risk of occupational accident on aircraft paint removal workers in PT. X. One's attitude is also determined by the knowledge possessed. One's knowledge will determine the attitude embodied in a concrete action. In addition, when a worker has a positive attitude in doing his job, it is because the worker has a good knowledge of his work as well. ${ }^{[10]}$ Such positive attitudes will also turn into actions that are also psychoacitive if they obtain social support and are also cornered with the availability of facilities.

\section{Effect of action on the risk of occupational injury}

There is influence of worker action to the risk of occupational accident on aircraft paint removal workers in PT. X. The wrong method of work can pose a danger to the workers themselves and others around them, which can cause accidents. In the activity of aircraft paint removal in PT.X, accidents have happened in the form of blister sores on the skin of workers following contact with hot water. The accident occurs because co-workers do not carry out their work in accordance with the correct methods.

\section{CONCLUSION}

There is influence of knowledge, attitude and action on the risk of occupational accident among Aircraft Paint Removal workers in PT. X

\section{REFERENCES}

1. Meily L. Kurniawidjaja. Teori dan aplikasi kesehatan kerja. Jakarta: Penerbit Universitas Indonesia. 2010.

2. Lingard $\mathrm{H}$. The effect of first aid training on Australian construction workers' occupational health and safety motivation and risk control behavior. Journal of Safety Research. 2002 Aug 31;33(2):209-30.

3. Sit $\mathrm{T}$, Wong A, Tong C. The Impact of Line Maintenance Mechanics' Attitude, Behavioural Intentions, and Behaviour on Aircraft Safety: A Study of Two Aircraft Maintenance Companies in Hong Kong. Journal of Management Research. 2013 Apr 1;5(2):133. 
4. Manuele FA. Reviewing Heinrich: Dislodging two myths from the practice of safety. Professional Safety. 2011 Oct 1;56(10):52.

5. Choudhry RM, Fang D, Mohamed S. The nature of safety culture: A survey of the state-of-the-art. Safety science. 2007 Dec 31;45(10):993-1012.

6. Chauvin C, Lardjane S, Morel G, Clostermann JP, Langard B. Human and organisational factors in maritime accidents: Analysis of collisions at sea using the HFACS. Accident Analysis \& Prevention. 2013 Oct 31;59:26-37.

7. Neal A, Griffin MA. Safety climate and safety behaviour. Australian journal of management. 2002 Jun;27(1_suppl):67-75.
8. Eagly AH, Chaiken S. Attitude strength, attitude structure, and resistance to change. Attitude strength: Antecedents and consequences. 1995;4:413-32.

9. Cheng CW, Lin CC, Leu SS. Use of association rules to explore cause-effect relationships in occupational accidents in the Taiwan construction industry. Safety science. $2010 \mathrm{Apr}$ 30;48(4):436-44.

10. Saari LM, Judge TA. Employee attitudes and job satisfaction. Human resource management. 2004Dec1;43(4):395-407. 